\title{
Impact of an educational intervention in enhancing nurses' knowledge towards psychiatric patients' ethical and legal rights
}

\author{
Amal Ibrahim Khalii*1,2, Rawan Felemban ${ }^{2}$, Rawan Tunker ${ }^{2}$ \\ ${ }^{1}$ Psychiatric and Mental Health Nursing, Menoufyia University, Egypt \\ ${ }^{2}$ College of Nursing, King Saud University for health sciences, Jeddah, Saudi Arabia
}

Received: March 12, 2019

Accepted: June 3, 2019

Online Published: July 4, 2019

DOI: $10.5430 /$ jnep.v9n10p1

URL: https://doi.org/10.5430/jnep.v9n10p1

\begin{abstract}
Background and objective: The management of psychiatric patients and the law of ethic already exists. Therefore, nursing ethics are necessary for psychiatric nurses since they are involved in providing services that impact human life. The aim was to evaluate the effectiveness of an educational program in enhancing nurses' knowledge regarding their responsibilities toward psychiatric patients' ethical and legal rights.

Methods: A quasi experimental study design with one group pre/post was used with 30 nurses recruited conveniently from Psychiatric Hospital Jeddah, Saudi Arabia. Nurses were questioned using 5 short answer questions, 11 multiple choice questions and the Structured Knowledge Questionnaire developed by Kumar, Mehta, and Kalra (2011).

Results: A total of 30 nurses were recruited, with their age ranging between 25-54 years old; the majority (59.4\%) were married, while $78.1 \%$ neither have psychiatric nursing experiences nor did they study ethics during their undergraduate years. The total mean score of pre-knowledge questionnaire was $27.2 \pm 2.97$ compared to $30.2 \pm 2.40$ in post assessment, with a significant difference between pre and post assessment. On the other hand, the total mean percentage of nurse's theoretical background in pre assessment was $25 \%$ compared with $29 \%$ with no significant difference between pre and post interventions.

Conclusions: Nurses' knowledge was inadequate regarding ethical and legal rights. The current study findings evidenced the effectiveness of the educational intervention in changing the nurses' knowledge significantly. Therefore, it is a necessity to ensure that nurses working in psychiatric hospitals have the necessary expertise regarding the legal and ethical issues involved with caring for psychiatric patients, to decrease the effects of malpractices and negligence in psychiatric nursing practice.
\end{abstract}

Key Words: Human rights, Knowledge, Interventions, Nurses, Psychiatric patients, Program

\section{BACKGROUND}

Nursing ethics are necessary as they are concerned with providing services that impact not only the life but also the health of the patient. Some of the situations a nurse encounters in practice, pose a dilemma that if not well handled, may impact negatively on the client and those who are concerned.
Therefore, in any nursing profession, knowledge of ethics is required to guide the performance. More specifically, ethical and legal rights of psychiatric patients should be considered crucial in nursing education and should be followed in delivering care. ${ }^{[1]}$

Accordingly, ethical knowledge enables nurses to distinguish Egypt.

*Correspondence: Amal Ibrahim Khalil; Email: amalkhalil34@yahoo.com; Address: Psychiatric and Mental Health Nursing, Menoufyia University, 
the proper way to deal with the patient. This includes respect, humanized behavior, and prioritizing of the principles of bioethics and the right of health services. ${ }^{[2]}$

Shockingly however, the nurses who had minimal knowledge about the ethical rights - especially about patient privacy and informed consent-lacked commitment to their ethical responsibilities. Therefore, it is important to explore the nurses' knowledge regarding their duties toward patients' rights. This was emphasized by Lilja et al. ${ }^{[3]}$ who reported that the relationship between the nurse and the patient is considered as an important task in psychiatric care as it is not only professional, but also therapeutic.

According to Shrestha and Jose, ${ }^{[4]}$ there are major principles of ethics that must be taken into consideration while providing care to psychiatric patients. This includes beneficence which refer to doing good while keeping the patient's interest as a priority, as well as non-malfeasance, which simply means causing no harm. The principle of non- malfeasance also covers reporting suspected abuse to prevent further victimization and protecting patients from chemically impaired nurses and other healthcare practitioners. Nurses must therefore maintain a competent practice level that prevents injury to the patient.

In addition, autonomy speaks for the right of the patient to make their own decisions, while they're given choices and treatment modalities for specific conditions. Thereby, competent adults have the freedom to consent or to refuse treatment. Nurses must respect the nurslings' wishes, even if they do not agree with them. Another patient right is fidelity which is the act of maintaining loyalty and commitment to the patient. Veracity on the other hand, is the duty to communicate truthfully. Finally, justice requires that all clients be treated equally and fairly. In fact, nurses face issues of justice daily when organizing care for their patients, deciding the time spent with each of them based on their needs, and fairly distributing resources. ${ }^{[5]}$

In India, Kumar, Mehta, and Kalra ${ }^{[6]}$ reported that $65 \%$ of psychiatric nurses have a moderate knowledge about patients' rights at Kochi, with one third possessing a high level of knowledge about the rights. Hence, psychiatric nurses' clearly play a significant role in protecting patients' rights as they are the ones who spend the greatest amount of time with the patients whilst meeting all their physical and emotional needs. They also possess the responsibility of explaining patients their rights regarding confidentiality, consent and receiving proper treatment. Therefore, all nurses regardless of their specialty must encounter some ethical challenges while providing care for patients. ${ }^{[7]}$
In fact, it was reported by Iglesias, and Vallejo ${ }^{[8]}$ that ethical issues usually make nurses feel extremely stressed and uncomfortable during patient care. In a pre/post research study done by Aliyu1 et al. ${ }^{[2]}$ that focused on the knowledge, and attitudes of nurses in relation to healthcare ethics and nursing legal regulations, it was discovered that nurses feel very anxious about situations that include ethical and legal conflicts and they admit that they need more training about their responsibilities regarding the topic. This could be due to the fact that, there are numerous different areas within psychiatric clinical settings where nurses are bound to face ethical and legal challenges. This includes using physical restraint and seclusion in mental health settings, withdrawing of treatment, involuntary admission and involving patients in long term care. ${ }^{[9]}$

Ulrich et al. ${ }^{[10]}$ identified the factors that lead to stigmatization. These included a lack of knowledge, negative attitude, and the avoiding behavior of the community towards mentally ill patients. All of which subsequently results in a stereotyped attitude such as that regarding the "inability" of schizophrenic patients to control, or take care of themselves. Patients are also labeled in public and viewed as "polluted" and "dangerous". Not only that, but most of the people diagnosed with mental illness face discrimination on the hands of mental health professionals themselves.

Additionally, this research showed how the different modes to obtain more knowledge about the legal and ethical practices is affected by the age of the participants. It was reported that nurses less than 30 years old obtained knowledge in legal and ethical issues through their university nursing studies, while older nurses obtained knowledge through experience, courses or seminars, alongside their own effort. Moreover, the nurses mentioned that the preferred teaching modes about the ethical and legal aspects of nursing include presentations, focus groups, workshops, lectures, specialized journals, books, mass media and manuals.

\subsection{Significance of the study}

The importance of nursing ethics has been established as it presides the performance of nurses and health professionals in delivering care for patients in all healthcare arena .In the clinical setting of the current study, it was observed that nurses are holding a derogatory attitude toward patients, despite the regulation done by the Ministry of Health (MOH) in Saudi Arabia which highlights their responsibilities toward the patients' ethical and legal rights. Nurses should be knowledgeable in lawful and moral attributes of patients' nursing interventions. They are among the multidisciplinary team employed in mental health care settings to ensure the decrease in the length of patients' stay. ${ }^{[11]}$ It is thereby quite 
clear that ethical principles provide a foundation for nursing practices and a basis for decisions, while, considering the consequences and the universal moral principles when making clinical judgments. ${ }^{[12]}$ In fact, the application of ethical and patients' legal rights when delivering care is crucial for all nurses because it is not only emphases on the patients' rights but also, the superiority of interventions that, they will receive. Thereby, the current study will be investigating the effectiveness of an educational program to enhance nurses' knowledge and practices regarding psychiatric patients' ethical and legal rights.

\subsection{Aim of the study}

The current study aimed to evaluate the effectiveness of an educational program in enhancing nurses' knowledge toward psychiatric patients' ethical and legal rights.

More specifically:

- Assess the nurses' knowledge in relation to legal and ethical duties when dealing with psychiatric patients (Pre/Posttest).

- Implement the program.

- Find the association between nurses' knowledge with their demographic characteristics and study variables.

\subsection{Research questions}

- What is the level of nurses' knowledge regarding their responsibilities' of patient's ethical and legal rights?

- What are the nurses' levels of practice for ethical and legal patients' rights?

- What is the relationship between nurses' knowledge and their personal background?

- What are the relationship between study variables?

\subsection{Hypotheses}

(1) Nurses who will attend the educational program will show no difference between pre and post program in knowledge score of ethical and legal responsibilities' toward patient ethical and legal rights.

(2) Nurses who will receive the program will show no difference between pre and post program in the ability to specify the application of concepts and behaviors of ethical and legal rights of psychiatric patients.

\section{Methodology}

\subsection{Design}

A quasi-experimental research design where one group (pre/post) was used to achieve the objectives of the current study. By using this research design, researchers gathered data at the pretest, and make the comparison with posttest (i.e., the educational program on ethical and patients' legal rights) which was introduced.

\subsection{Setting and study population}

A non-probability convenient sampling technique was used to recruit a total of 30 nurses out of 49 the actual numbers working with the patients (total number of nurses in the hospital 100). The recruited nurses are working in Jeddah Psychiatric Hospital affiliated to Ministry of Health, Saudi Arabia. Those nurses were then divided into 6 wards including inpatient male, female psychiatric wards, outpatient and emergency department. The hospital is located on Almahjar district south Jeddah city. It is the only psychiatric hospital in the city providing services for psychiatric patients and their families. It provides emergency, outpatient and inpatient services. The capacity of the hospital is a total of 120 beds with 49 staff nurses who have been involved in the patient care. The majority of nurses' educational qualification is diploma of nursing (associate degree), where only 14 are holding a bachelor degree in nursing.

\subsection{Tools of the study}

A Self-administer Knowledge Questionnaire Sheet consisted of 3 sections as follows:

The first section: The demographic sheet which was developed through relevant literature search, and was included eight elements which questioned the nurses about their demographic background such as age, sex, marital status, total years of experience including professional experience in psychiatric nursing, educational qualification, in-service education, training workshops, and training courses specified in nursing ethics.

The 2nd section: A modified self-administered questionnaire based on a study done by Kumar, Mehta, and Kalra ${ }^{[6]}$ and Osingada et al. ${ }^{[13]}$ and Hafez, Mohamed, and Eltabey ${ }^{[14]}$ after their official permission via email to assess nurses' knowledge of ethical and legal patients' rights. The first part included 16 questions:

(a) 5 short answer questions including: meaning of nursing ethics, principles of bioethics, definition of informed consent, moral and ethical theories, and definition of veracity and confidentiality. Every correct answer will be awarded a mark.

(b) 11 MCQ questions used to assess participants' knowledge of basic concepts in nursing ethics and their application in nursing care. Subjects responses will then be evaluated by giving a score of 1 for the correct answer and (zero) for the wrong answer. Therefore, the range was 0-16. Knowledge 
will be considered satisfactory if the percent score was $60 \%$ or more, and unsatisfactory if it is less than $60 \%$. According to the Osingada et al. ${ }^{[13]}$ the questionnaire was evaluated, pre-coded, and pre-tested, before using it in their study.

The 3rd section: A structured knowledge questionnaire. A modified tool of a Structured Knowledge Questionnaire regarding the legal and ethical responsibilities in the field of psychiatric nursing, which was developed by Kumar, Mehta, and Kalra. ${ }^{[6]}$ The questionnaire comprised of 60 items, to be answered in dichotomous responses either "True" or "False", where (1) is used for correct response and zero for the incorrect. For the current study purpose, 35 items out of 60 (the original tool) were adopted. 28 items were used to evaluate the response of the staff nurses regarding legal and ethical knowledge in psychiatric area. It comprises the nurses' ethical responsibilities which were categorized under the domains of knowledge and application of bioethical behaviors such as, confidentiality, informed consent, substituted consent, privacy, standard of care, and etc. In addition, 7 items were used to evaluate the staff nurses in relation to the application of legal knowledge in psychiatric area. It was concerned with nurses' knowledge and their role in various acts, such as tort, battery, assault, etc. The validity was established by Kumar, Mehta, and Kalra ${ }^{[6]}$ and, the reliability came out to be 0.78 . The same scoring system was used according to Kumar, Mehta, and Kalra ${ }^{[6]}$ with a modification in the score which was done based on 36 items as the range was 0-36, which was categorized into 3 levels: Low (0-10) moderate (11-22) and high (23-36).

\subsection{Validity and reliability}

The tools of the current study were tested for reliability and validity by the original developers. For the purpose of English language barriers observed in nursing staff, the tools were translated into Arabic language and then back to English language. Back translation aimed to verify whether the translation covers all aspects of the original English version of the questionnaire or not. Then, to ensure the content validity and reliability, the final translated Arabic version of the questionnaires was evaluated by a panel of experts who were selected on the basis of their qualifications and experience in nursing research and education.

\subsection{Pilot study}

The tools were piloted and tested by 10 participants who were included in the study sample. Pilot study was done to check for the tools' clarity, feasibility, practicability, the time required for completing the questionnaire. and any difficulties that might be encountered by the participants in reading or understanding the questions. The results of the pilot study was calculated and reliability Cronbach alpha coefficient were 0.83, and 79.0 (A structured Knowledge Questionnaire and MCQ of Osingada et al. ${ }^{[13]}$ respectively).

\subsection{Data collection procedure} (1) Program description

The program was developed based on dearth review of literature to include the necessary information which can enhance nurses' knowledge toward ethical and legal practices used in delivering nursing interventions to psychiatric patients. Since, nurses exert significant effort from the time of patients' admission to their discharge, and they may face multiple conflicts and challenges to make an ethical decision regarding different behaviors exhibited by the patients, which can increase nurses' anxiety levels.

By the end of this program, participants were expected to be able to:

- Act as a knowledgeable person about ethical and legal responsibilities.

- Recognize the different concepts in relation to ethical and legal knowledge.

- Be aware and can manage the situations that may lead to ethical dilemma.

- Identify their rights to protect themselves from patients' aggressive and acting out behaviors.

- Follow the steps of ethical decision making, problem solving and assertiveness behaviors that can help them to face the ethical and legal challenges successfully.

\section{(2) The procedure}

\section{Pre-test administration}

- An approval to conduct the study was taken from the director of Jeddah Psychiatric hospital, and the nursing supervisors of each department in the hospital.

- Ethical issues were raised by taking verbal and written consent for the participation of every nurse after explaining the aim of the study and confirming the confidentiality of their data.

- Nurses of studied group were asked to fill the questionnaire at the beginning of the first day of data collection (i.e., before the theoretical session starts) and at the end of the day (after the clinical practicum sessions).

- A letter with all the details was displayed on bulletin boards at the hospital to encourage nurses to participate in the study. The nurses who were willing to participate registered their names with the nurse-manager.

- The data were collected during summer 2017 and after receiving the approval.

ISSN 1925-4040 E-ISSN 1925-4059 


\section{Program implementation}

The program was conducted in 2 sessions:

- The educational program was conducted for 6 hours/day. These 6 hours were divided into 2 sessions which were as follows:

- The first session was used for the theoretical part of ethical and legal rights including definition, importance, terminology (confidentiality, informed consent, veracity, beneficence, non-maleficence, and fidelity), least restrictive methods, and patients' ethical rights and legal practices. The first session took 3 hours divided into small sessions. Each session was 80 minutes long with a 10-20 minutes break in between.

- The second session covered the clinical evidences which involved legal and illegal practices as well as examples on ethical and unethical violation of the patient rights. This session was issued in 2 parts (one about the legal practices and the other about ethical violation of the patient's rights) which were 60 minutes each, with half an hour given for discussion. Methods of instructions were included power point presentations, videos and clinical simulation for unethical and illegal practices of assault, battery, false imprisonment, negligence and malpractices.

- Post test administration: questionnaires were filled by the nurses again after implementing the program.

\subsection{Ethical considerations}

An official approval from the manager of Psychiatric Hospital Jeddah affiliated to Ministry of Health, Jeddah, Saudi Arabia was received. In addition to the approval from the nurses' manager of Psychiatric Hospital for data collection. The nurses were informed about the purpose of the study, and that their participation is voluntary and that they can withdraw from the study at any time. A written consent was also obtained from all the participants. Moreover, anonymity was ensured by using identification codes on the questionnaires that facilitated individual comparison of pre and post educational intervention responses.

\subsection{Data analysis}

The data were coded and analyzed using SPSS version 22. Data were presented by descriptive statistics for discrete variables in the form of frequencies and percentages, and for interval and ratio variables in the form of means and standard deviations. A paired $t$-test will be used to analyze the total scores of the participants' responses on the pre-test and the post-test (i.e., before and after the educational intervention). Participants' sociodemographic and knowledge differences will also be analyzed using Chi-Squared test $\left(\chi^{2}\right)$. Pearson $r$ Published by Sciedu Press was used to test the correlation between nurses' knowledge and their sociodemographic background.

\section{RESULTS}

Table 1 represented the distribution of sociodemographic personal information of nurses. The mean age was $33.90 \pm$ 8.36. On analysis of educational status $72.9 \%$ were Diploma nurses, $23.3 \%$ were B.Sc. nurses. More than two thirds of the subjects $(63.3 \%)$ were married. With regard to the years of work experience of nurses, $63 \%$ of nurses had 1-8 years of working experience in psychiatric setting and $16.6 \%$ of nurses had 9-15 years of experience compared with $20 \%$ who had their experiences from general hospitals. As regard to the ethics course in undergraduate, the majority was studied in their teaching curriculum and $50 \%$ was distributed between attending or benefit from any psychiatric workshop on ethics profession, whereas the majority $73.3 \%$ didn't attend workshops in ethics of profession during their working experiences.

Table 1. Sociodemographic data for participants in the study: $(\mathrm{N}=30)$

\begin{tabular}{|c|c|c|}
\hline \multirow{2}{*}{$\begin{array}{l}\text { Variable } \\
\text { 1-Age }\end{array}$} & \multicolumn{2}{|c|}{ Mean } \\
\hline & \multicolumn{2}{|c|}{$33.90 \pm 8.36$} \\
\hline Variable & No. & $\%$ \\
\hline 2-Marital status & 11 & 36.7 \\
\hline Single & 19 & 63.3 \\
\hline Married & & \\
\hline \multicolumn{3}{|l|}{ 3-Education level } \\
\hline Nursing diploma & 23 & 72.9 \\
\hline Bachelor degree & 7 & 23.3 \\
\hline \multicolumn{3}{|l|}{ 4-Years of experience } \\
\hline No. of experience in general & 6 & 20 \\
\hline \multicolumn{3}{|c|}{ No. of experience in psychiatric hospital } \\
\hline Experiences of $1 \mathrm{Y}-<8 \mathrm{Y}$ & 19 & 63.3 \\
\hline Experiences of $9 \mathrm{Y}-<15 \mathrm{Y}$ & 5 & 16.6 \\
\hline \multicolumn{3}{|l|}{ 5-Studied ethics } \\
\hline Yes & 27 & 90 \\
\hline No & 3 & 10 \\
\hline \multicolumn{3}{|c|}{ 6-Attending any psychiatric nursing workshops } \\
\hline Yes & 15 & 50 \\
\hline No & 15 & 50 \\
\hline \multicolumn{3}{|l|}{ 7-Workshop benefit } \\
\hline Yes & 15 & 50 \\
\hline No & 15 & 50 \\
\hline \multicolumn{3}{|c|}{ 8-Workshop on ethics of profession } \\
\hline Yes & 8 & 26.7 \\
\hline No & 22 & 73.33 \\
\hline
\end{tabular}

Table 2 showed staff nurses' knowledge related to the basic knowledge about the meaning of ethics, principle of bioethics, informed consent, veracity and confidentiality definition. The table revealed that, there was a significant 
differences between pre/posttest responses as regard to all respectively at $p$ value $\leq .05$. questions as $(t=-5.510 ;-3.148 ;-8.622 ;-5.298$, and -2.575$)$

Table 2. Nurses' knowledge related to basic nursing ethics (short answer) $(\mathrm{N}=30)$

\begin{tabular}{|c|c|c|c|c|c|c|c|c|c|c|}
\hline \multirow{3}{*}{ Questions } & \multirow{2}{*}{\multicolumn{2}{|c|}{$\begin{array}{l}\text { Pre } \\
\text { Correct }\end{array}$}} & \multirow{2}{*}{\multicolumn{2}{|c|}{$\begin{array}{l}\text { Post } \\
\text { Incorrect }\end{array}$}} & \multirow{2}{*}{\multicolumn{2}{|c|}{$\begin{array}{l}\text { Pre } \\
\text { Correct }\end{array}$}} & \multirow{2}{*}{\multicolumn{2}{|c|}{$\begin{array}{l}\text { Post } \\
\text { Incorrect }\end{array}$}} & \multirow{3}{*}{$t$} & \multirow{3}{*}{ Sig. } \\
\hline & & & & & & & & & & \\
\hline & No & $\%$ & No & $\%$ & No & $\%$ & No & $\%$ & & \\
\hline 1-What does nursing ethics mean? & 3 & 10 & 12 & 40 & 27 & 90 & 18 & 60 & -5.51 & .000 \\
\hline 2-List the four principles of bioethics & 15 & 50 & 18 & 60 & 15 & 50 & 12 & 40 & -3.148 & .005 \\
\hline 3-Define informed consent? & 8 & 26.6 & 15 & 50 & 22 & 73.3 & 15 & 50 & -8.622 & .000 \\
\hline 4-What does the concept veracity mean? & 15 & 50 & 20 & 66.6 & 15 & 50 & 10 & 33.3 & -5.29 & .000 \\
\hline $\begin{array}{l}\text { 5-A nurse who discloses a patient } \\
\text { information to a colleague in a taxi } \\
\text { violates a patient right? }\end{array}$ & 14 & 46.6 & 19 & 63.3 & 16 & 53.3 & 11 & 36.6 & -2.57 & .016 \\
\hline
\end{tabular}

Table 3 revealed that, the 11 MCQ questions which were used to assess nurses' knowledge of basic concepts in nursing ethics and their application in nursing care. The results reported that, the majority, $96.66 \%$ and $93.33 \%$ respectively, identified correctly that, checking medication rights before giving medication was an important to promote accountability of nurses and that, the definition of ethics was "The personal conviction that something is absolutely right or wrong in all situations" in pre assessment with a high significant difference between pre and post intervention as $p=$ .000 . On the other hand, almost $100 \%$ of nurses' response were correct regarding the identification of the concept of justice, confidentiality, and non-maleficence in the pre assessment with a high significant difference between pre and post assessment as $t=14.47,8.651$; and 6.513 respectively with $p=.000$. Additionally, $100 \%$ of nurses' responses were incorrect regarding the identification of "When does a moral issue become an ethical issue?" in pre assessment with high significant difference between pre and post interventions as $t$ $=6.72$ and $p \leq .05$.

Figure 1 illustrated the significant difference between the total mean score of pre and post interventions assessment regarding ethical and legal issues and its application in psychiatric area.

Table 4 revealed the nurses' response related to the application of legal knowledge within the psychiatric arena. It was reported that, a highly significant difference between pre and post intervention was found regarding the nurses' identification of that law doesn't adapt to the rights of the patients, any physical attack is not an intentional tort, and that every written statement that hurts an individual's repute is known as: Slander, related to the knowledge on legal aspects of psychiatric nursing at $p \leq .05$. On the other hand, there was no significant difference between pre and post in6 tervention of correct responses related to nurses' knowledge about the actions of mental health, state licensure policy, various governmental/statutory and professional bodies dealing with mental illnesses, and the legal age for giving consent for ECT procedure. Moreover, only $46.7 \%$ of nurses gave the correct answer to what the law describes as allowable and non-allowable activities in the nursing practice, tort and about disregarding gifts in return of care during the discharge of patient, with no significant difference between pre and post interventions at $p \leq .05$.

Table 5 indicated the nurses' responses to knowledge related to ethics in psychiatric area. The results revealed that, the only significant difference was found in asking nurses whether "psychiatric nurses should have a therapeutic relationship, and communication skills comparing to general nurses", as $83.3 \%$ correctly responded in pre assessment compared to $96.7 \%$ in post assessment with $t=2.11$ at $p=$ .043 .

Table 6 representad the responses' of the nurses regarding their use of legal information in psychiatric setting. It showed that, the majority $93.3 \%, 83.3 \%$ and $80 \%$ respectively, of nurses felt capable to apply knowledge while preventing malpractice during nursing care of the patient, the awareness regarding various law terminologies, and handling psychiatric records as an important document with no significant difference between pre and post assessment interventions as $p \geq .05$. Whereas, the significant difference was detected between nurses' pre and post intervention in the items of "nurses identification of negligence concept, the intentional tort when giving medication without observing patients' side effects, and that the consent could be taken either from patients or their guardians as $t=4.097 ; 4.097 ; 2.757$ at $p=.000$ and .010 respectively. 
Table 3. Nurses' knowledge of basic concepts in nursing ethics and their application in nursing care $(\mathrm{n}=30)$

\begin{tabular}{|c|c|c|c|c|c|c|}
\hline \multirow{2}{*}{ Question } & \multicolumn{2}{|l|}{ Pre } & \multicolumn{2}{|l|}{ Post } & \multirow{2}{*}{$t$} & \multirow{2}{*}{ Sig. } \\
\hline & Correct & Incorrect & Correct & Incorrect & & \\
\hline $\begin{array}{l}\text { 1-A patient is diagnosed with a terminal cancer; his } \\
\text { family asked his nurse to explain to him his illness on } \\
\text { their behalf. What principle guides this situation? }\end{array}$ & 2 & 28 & 13 & 17 & 2.797 & .009 \\
\hline $\begin{array}{l}\text { 2-A nurse who accepts to participate in a television } \\
\text { commercial while wearing her uniform violates; }\end{array}$ & 0 & 30 & 20 & 10 & 5.408 & .000 \\
\hline $\begin{array}{l}\text { 3-The following statements below are acts of nursing } \\
\text { negligence, except }\end{array}$ & 3 & 27 & 20 & 10 & 8.499 & .000 \\
\hline $\begin{array}{l}\text { 4-Standards we use to determine right from wrong, or } \\
\text { good from bad behavior are known as: }\end{array}$ & 12 & 18 & 7 & 23 & 7.208 & .000 \\
\hline 5-Informed consent is a process that promotes & 14 & 16 & 17 & 13 & 2.333 & .027 \\
\hline $\begin{array}{l}\text { 6-Before the nurse administered the client's medication } \\
\text { she assessed the client's needs for the drug, and } \\
\text { followed the "rights" in drug preparation and } \\
\text { administration. After the nurse has given the dose, she } \\
\text { evaluated the client's response to the medication given. } \\
\text { The nurse is promoting: }\end{array}$ & 28 & 2 & 2 & 28 & 14.748 & .000 \\
\hline $\begin{array}{l}\text { 7-The personal conviction that something is absolutely } \\
\text { right or wrong in all situations is called: }\end{array}$ & 29 & 1 & 9 & 21 & 6.470 & .000 \\
\hline 8-The duty to respect privileged information is called & 0 & 30 & 26 & 4 & 14.472 & .000 \\
\hline 9-When does a moral issue become an ethical issue & 0 & 30 & 11 & 19 & 6.728 & .000 \\
\hline $\begin{array}{l}\text { 10-Nurse } \mathrm{X} \text { avoids deliberate harm, risk of harm that } \\
\text { occurs during his performance of nursing actions. The } \\
\text { nurse is promoting which of the following }\end{array}$ & 1 & 29 & 19 & 11 & 8.651 & .000 \\
\hline $\begin{array}{l}\text { 11-The nurse in a unit is caring for several patients. To } \\
\text { distribute nursing care the nurse utilizes the principle of } \\
\text { triage due to the limited availability of resources. The } \\
\text { nurse is promoting which of the following: }\end{array}$ & 1 & 29 & 18 & 12 & 6.513 & .000 \\
\hline
\end{tabular}

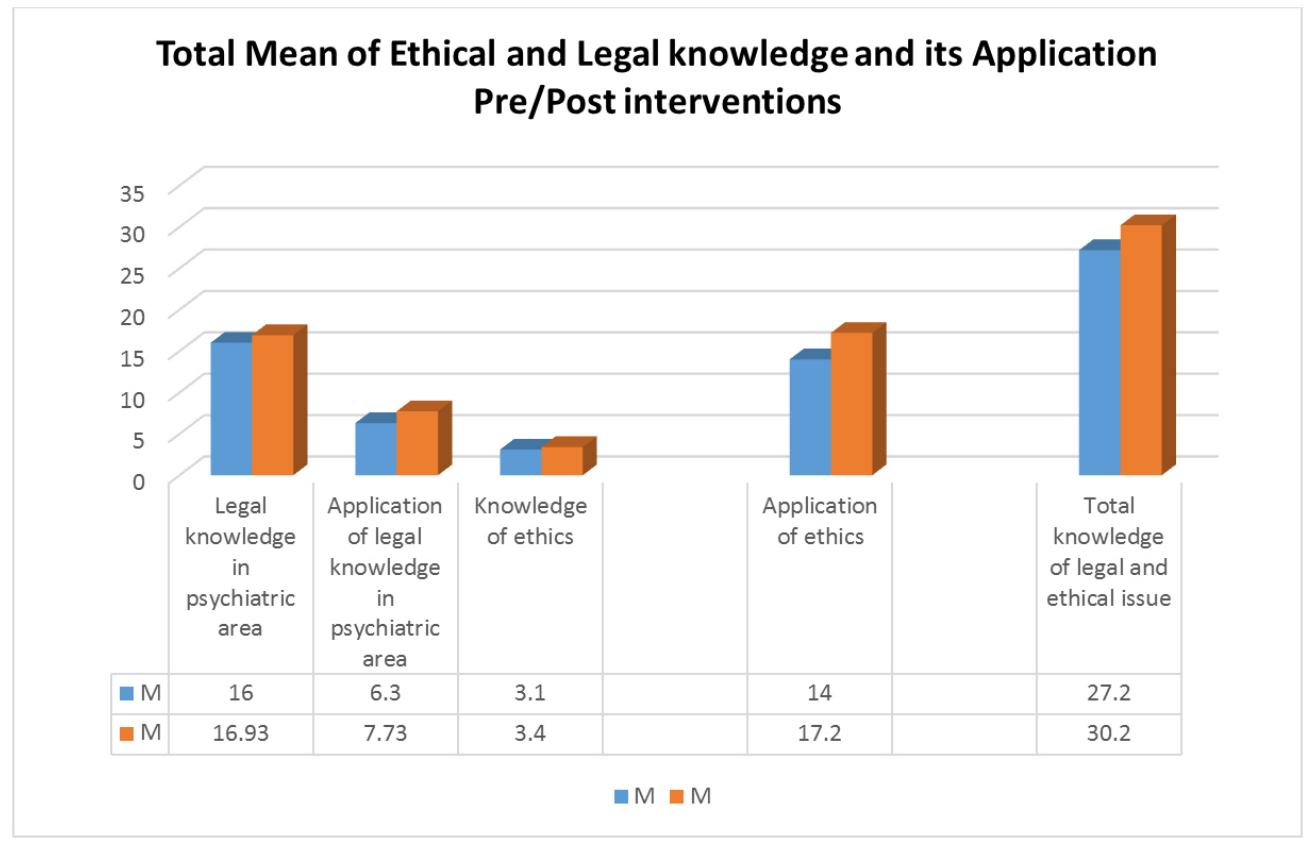

Figure 1. Total mean of ethical and legal knowledge and its application pre/post intervention 
Table 4. Nurses' responses to legal knowledge in psychiatric area $(n=30)$

\begin{tabular}{|c|c|c|c|c|c|c|}
\hline \multirow{2}{*}{ Variables } & \multicolumn{2}{|l|}{ Pre } & \multicolumn{2}{|l|}{ Post } & \multirow{2}{*}{$t$ test } & \multirow{2}{*}{$p$ value } \\
\hline & True $\%$ & False \% & True $\%$ & False \% & & \\
\hline 1-Law does not conform to the right of client. & 96.7 & 3.3 & 98.66 & 2.2 & 5.809 & $.000 * *$ \\
\hline $\begin{array}{l}\text { 2-A nurse should have full information regarding state nursing } \\
\text { licensure policy. }\end{array}$ & 93.3 & 6.7 & 100 & 0.0 & 1.439 & .161 \\
\hline 3-Assault is not an intentional tort & 60.0 & 40.0 & 83.3 & 16.7 & 2.249 & $.032 *$ \\
\hline $\begin{array}{l}\text { 4-The law states allowed and not allowed behaviors in the } \\
\text { nursing practice. }\end{array}$ & 46.7 & 53.3 & 70.0 & 30 & 1.756 & .090 \\
\hline $\begin{array}{l}\text { 5-A younger (below } 18 \text { years) cannot give assent for any } \\
\text { procedure like ECT or any others s in Psychiatric nursing arena. }\end{array}$ & 90.0 & 10.0 & 93.3 & 6.7 & .441 & .662 \\
\hline $\begin{array}{l}\text { 6-Psychiatric Nurses are lawfully indebted to keep } \\
\text { confidentiality to all patients' information }\end{array}$ & 90 & 10 & 96.7 & 3.3 & -1.000 & .326 \\
\hline $\begin{array}{l}\text { 7-Which of the following regulation states that "The person at } \\
\text { the time of the criminality did not identify the nature and quality } \\
\text { of the act (cannot distinguish between what is incorrect and what } \\
\text { is correct) shall not be illegal". }\end{array}$ & 66.7 & 33.3 & 76.7 & 23.3 & -.828 & .415 \\
\hline $\begin{array}{l}\text { 8-The nurse shouldn't accept gifts from patients' relative on the } \\
\text { time of discharge from patient relative in favor of their care. }\end{array}$ & 70 & 30 & 76.7 & 23.3 & -.571 & .573 \\
\hline $\begin{array}{l}\text { 9-Slander is considered as Any written communication that } \\
\text { injures an patient's character }\end{array}$ & 90 & 10 & 90 & 10 & 1.000 & .000 \\
\hline $\begin{array}{l}\text { 10-Touching patients without his consent or permission named } \\
\text { as Battery. }\end{array}$ & 93.3 & 6.7 & 86.7 & 13.3 & 1.000 & .326 \\
\hline $\begin{array}{l}\text { 11-The key devotion for regulating psychiatric nursing practice } \\
\text { is to safeguard: The patient } \& \text { nurse }\end{array}$ & 90 & 10 & 90 & 6.7 & -.441 & .663 \\
\hline $\begin{array}{l}\text { 12-A nurse should identify the various legislature actions } \\
\text { followed in psychiatric setting before starting job duty. }\end{array}$ & 90.0 & 10 & 96.7 & 3.3 & 1.000 & .326 \\
\hline $\begin{array}{l}\text { 13-Psychiatric hospital like general hospital has its own policy, } \\
\text { philosophy and regulation regarding the care of mentally ill } \\
\text { individuals. }\end{array}$ & 86.7 & 13.3 & 93.3 & 6.7 & -.812 & .423 \\
\hline $\begin{array}{l}\text { 14-Admission and discharge procedure in psychiatric unit is } \\
\text { different than in general hospital. }\end{array}$ & 70 & 30 & 90 & 10 & -1.989 & .054 \\
\hline
\end{tabular}

Table 5. Nurses' responses to knowledge related to ethics in psychiatric area $(n=30)$

\begin{tabular}{|c|c|c|c|c|c|c|}
\hline \multirow{2}{*}{ Variables } & \multicolumn{2}{|l|}{ Pre } & \multicolumn{2}{|l|}{ Post } & \multirow{2}{*}{$t$ test } & \multirow{2}{*}{$p$ value } \\
\hline & True \% & False \% & True \% & False \% & & \\
\hline $\begin{array}{l}\text { 1-Confining the patient to a bed against his/her well, is known as } \\
\text { false imprisonment. }\end{array}$ & 90 & 10 & 96.7 & 3.3 & 1.000 & .326 \\
\hline $\begin{array}{l}\text { 2-A psychiatric nurse should have special skills such as good } \\
\text { therapeutic relationship, and communication developing skills } \\
\text { alike to non-psychiatric nurse. }\end{array}$ & 83.3 & 16.7 & 96.7 & 3.3 & 2.112 & $.043 *$ \\
\hline $\begin{array}{l}\text { 3-Dealing with mentally ill patient is not same as caring with } \\
\text { other patients. }\end{array}$ & 86.7 & 13.3 & 96.7 & 3.3 & 1.361 & .184 \\
\hline
\end{tabular}

Table 7 depicted the items wise responses of the staff nurses regarding the application of ethics in the field of psychiatric nursing. It was reported that, an equal number of the majority (93.3\%) of nurses demonstrated correctly the concept of negligence and the importance of meeting the basic and psychological needs, of psychiatric patient at the time of admission, with no significant difference between pre and post assessment response at $p=.161$. On the other hand, the significant differences between pre and post response of nurses ability to realize that every newly admitted patient has the right for orientation, and they also agree that the selection of activities could violate the client's privacy: talking about client in public place at $p=.043$ and .009 respectively. Surprisingly, only $13.3 \%$ answered correctly 
regarding the consent of a violent patient who did not have rectly responded in the post intervention with no significant any relative along with them, compared to $90.0 \%$ who cor- difference at $p=.325$.

Table 6. Nurse's responses to application of legal knowledge in psychiatric area $(n=30)$

\begin{tabular}{|c|c|c|c|c|c|c|}
\hline \multirow{2}{*}{ Variables } & \multicolumn{2}{|l|}{ Pre } & \multicolumn{2}{|l|}{ Post } & \multirow{2}{*}{$t$ test } & \multirow{2}{*}{$p$ value } \\
\hline & True $\%$ & False $\%$ & True $\%$ & False $\%$ & & \\
\hline $\begin{array}{l}\text { 1-Defilement of any law concerning the patient care by a } \\
\text { registered nurse can be said as Misconduct. }\end{array}$ & 83.3 & 16.7 & 90 & 6.7 & 1.140 & .264 \\
\hline $\begin{array}{l}\text { 2-Malpractice occurs when a nurse fail to work responsibly that } \\
\text { lead to harm of the clients. }\end{array}$ & 93.3 & 6.7 & 96.7 & 3.3 & .571 & .573 \\
\hline $\begin{array}{l}\text { 3-When depressive patient commits suicide, the nurse can be } \\
\text { indicted under: Negligence }\end{array}$ & 63.3 & 36.7 & 100 & 0 & 4.097 & $.000^{*}$ \\
\hline $\begin{array}{l}\text { 4-When a Nurse managing the psychiatric medicine without } \\
\text { noting the side effect: it will be type of intentional tort. }\end{array}$ & 50 & 50 & 93.3 & 6.7 & 4.709 & $.000^{*}$ \\
\hline 5-Documents in mental care setting considered as lawful records. & 80 & 20 & 96.7 & 3.3 & 1.980 & .57 \\
\hline $\begin{array}{l}\text { 6-Consent refers to an approval given by another person, being a } \\
\text { guardian assigned by law court or kith and kin on behalf of the } \\
\text { patient: Substituted consent }\end{array}$ & 56.7 & 43.3 & 86.7 & 13.3 & 2.757 & $.010^{*}$ \\
\hline
\end{tabular}

Table 7. Nurses' responses to application of ethics in psychiatric area $(n=30)$

\begin{tabular}{|c|c|c|c|c|c|c|}
\hline \multirow[b]{2}{*}{ Variables } & \multicolumn{2}{|l|}{ Pre } & \multicolumn{2}{|l|}{ Post } & \multirow[b]{2}{*}{$t$ test } & \multirow[b]{2}{*}{$p$ value } \\
\hline & $\begin{array}{l}\text { True } \\
\%\end{array}$ & $\begin{array}{l}\text { False } \\
\%\end{array}$ & $\begin{array}{l}\text { True } \\
\%\end{array}$ & $\begin{array}{l}\text { False } \\
\%\end{array}$ & & \\
\hline 1-Impairment to client's any stuff can be referred as Negligence & 93.3 & 6.7 & 96.7 & 3.3 & 1.439 & .161 \\
\hline $\begin{array}{l}\text { 2-There is a violation if relationship between nurse and patient or } \\
\text { physician exceeds the boundaries of therapeutic relationship }\end{array}$ & 60 & 40 & 90 & 10 & 1.000 & .326 \\
\hline $\begin{array}{l}\text { 3-A nurse should convene physiological and psychological needs, of } \\
\text { psychiatric patient on his/her admission. }\end{array}$ & 93.3 & 6.7 & 96.7 & 3.3 & 1.439 & .161 \\
\hline $\begin{array}{l}\text { 4-While getting approval for ECT from the patient, the nurse should: } \\
\text { ensure that patient's' knowledge is sufficient to give consent. }\end{array}$ & 33.3 & 66.7 & 86.7 & 13.3 & 1.439 & .161 \\
\hline $\begin{array}{l}\text { 5-Violation patient's confidentiality while performing a procedure like } \\
\text { ECT or administering drug constitute: Invasion of privacy. }\end{array}$ & 76.7 & 23.3 & 93.3 & 6.7 & 1.439 & .161 \\
\hline $\begin{array}{l}\text { 6-Poor management of administering an ECT will be viewed as: } \\
\text { unprofessional misconduct. }\end{array}$ & 53.3 & 46.7 & 90 & 10 & 1.000 & .326 \\
\hline 7-Orientation for the ward is one of the each newly admitted patients & 76.7 & 23.3 & 96.7 & 3.3 & 2.112 & $.043^{*}$ \\
\hline $\begin{array}{l}\text { 8-A confused client drops and fractures a hip while in the Psychiatric unit } \\
\text { due to client sedation in the night-time and the nurse unsuccessful to raise } \\
\text { the side rails of the bed. The nurse's conduct will be litigated under. } \\
\text { Negligence }\end{array}$ & 70 & 30 & 83.3 & 16.7 & 1.439 & .161 \\
\hline $\begin{array}{l}\text { 9-If a client is came to the emergency department with aggressive behavior } \\
\text { and needs an urgent chemical restrain but has no one of his family at that } \\
\text { time: Informed consent should be ignored. }\end{array}$ & 13.3 & 86.7 & 90 & 10 & 1.00 & .325 \\
\hline $\begin{array}{l}\text { 10-During a home visit you observed that a patient with developmental } \\
\text { disorder is being overmedicated: your moral obligations will be: ask for } \\
\text { instant medical support. }\end{array}$ & 63.3 & 36.7 & 96.7 & 3.3 & 1.000 & .326 \\
\hline $\begin{array}{l}\text { 11-You listen that one of your colleague is making ethnic speech about a } \\
\text { secluded patient, the most suitable technique to manage: Talk and educate } \\
\text { your co-worker in an assertive manner about social and ethical issue. }\end{array}$ & 40 & 60 & 93.3 & 6.7 & 1.439 & .161 \\
\hline $\begin{array}{l}\text { 12-when you are talking about your patient in public place is considered as } \\
\text { an activity that violate the client privacy }\end{array}$ & 40 & 60 & 53.3 & 23.7 & 2.833 & $.009 *$ \\
\hline
\end{tabular}

As shown in Table 8, the participants' marital status, level of While, the psychiatric total clinical experience $(p=.05)$ was education, attending psychiatric or ethics profession work- significantly related to the knowledge of the study subjects shops, and ethics studying of the nurses were not associated concerning the legal and ethical knowledge and the applicawith their knowledge level of ethical and legal practices. tion responsibility. 
Table 8. Correlation between demographic data and the study variables $(\mathrm{n}=30)$

\begin{tabular}{|c|c|c|c|c|c|c|c|c|c|}
\hline \multirow[t]{2}{*}{ Demographic } & & \multicolumn{2}{|c|}{$\begin{array}{l}\text { Legal } \\
\text { knowledge }\end{array}$} & \multicolumn{2}{|c|}{$\begin{array}{l}\text { Application of } \\
\text { legal knowledge }\end{array}$} & \multicolumn{2}{|c|}{$\begin{array}{l}\text { Knowledge } \\
\text { related to ethics }\end{array}$} & \multicolumn{2}{|c|}{$\begin{array}{l}\text { Application of } \\
\text { ethics }\end{array}$} \\
\hline & & Pre & Post & Pre & Post & Pre & Post & Pre & Post \\
\hline \multirow{2}{*}{ 1-Marital status } & $r$ & .016 & .304 & -.070 & .124 & .023 & .050 & .170 & .170 \\
\hline & sig & .935 & .109 & .717 & .514 & .904 & .793 & .398 & .398 \\
\hline \multirow{2}{*}{ 2-Education level } & $r$ & -.313 & -.292 & -.391 & -.489 & .051 & -.537 & -.221 & -221 \\
\hline & sig & .094 & -.124 & $.033^{*}$ & $.007 *$ & .788 & $.002 *$ & .268 & .268 \\
\hline \multirow{2}{*}{ 3-Years of experience } & $r$ & -.092 & .070 & .267 & .029 & 0.167 & .060 & .401 & .401 \\
\hline & sig & .718 & .627 & .161 & $.029 *$ & .752 & .037 & $.038 *$ & $.038^{*}$ \\
\hline \multirow{2}{*}{ 4-Studied ethics } & $r$ & .130 & -.202 & -.178 & -.212 & -.111 & -.040 & -.212 & -.212 \\
\hline & sig & .493 & .293 & .356 & .261 & .559 & .833 & .288 & .288 \\
\hline \multirow{2}{*}{$\begin{array}{l}\text { 5-Attending any psychiatric } \\
\text { nursing workshop }\end{array}$} & $r$ & -.267 & .073 & -.156 & .231 & -.333 & .120 & -.335 & -.335 \\
\hline & sig & .154 & .707 & .418 & .219 & .418 & .526 & .087 & .087 \\
\hline \multirow{2}{*}{$\begin{array}{l}\text { 6-Workshop profession } \\
\text { ethics }\end{array}$} & $r$ & .058 & .012 & .013 & -.102 & -.236 & .000 & .059 & .059 \\
\hline & sig & .760 & .952 & .948 & .591 & .210 & 1.000 & .770 & .770 \\
\hline
\end{tabular}

Table 9 showed the relationship between the total mean score of age $33.67 \pm 8.61$ and knowledge, of ethics and legal issues and its application. There was a negative significant correlation between age of the respondents and application of legal in pre assessment $(\mathrm{M} \pm \mathrm{SD} 27.4 \pm 8.69)$, knowledge related to ethics at pre $(30.34 \pm 8.60)$ and post $(30.65 \pm 8.49)(t$
$=16.652$ and $p=.000,18.994)$ and $p=.000$ respectively. While there was a positive significant relationship between age of the respondents and their application for ethics pre and post assessment with an equal mean of $19.1 \pm 8.11$ and $t=12.243$ and $p=.000$ as the older the age of the nurses, the more the application of ethics in the clinical setting.

Table 9. Correlation between age of the studied sample and their knowledge of ethics and legal application $(\mathrm{n}=30)$

\begin{tabular}{llll}
\hline Age & $\mathbf{M} \pm$ SD & $\boldsymbol{t}$ & Sig. (2- tailed) \\
\hline Application legal pre & $27.4 \pm 8.69$ & 16.652 & .000 \\
Knowledge related ethics pre & $30.34 \pm 8.60$ & 18.994 & .000 \\
Knowledge related ethics post & $30.65 \pm 8.49$ & 19.433 & .000 \\
Application of ethics pre & $19.1 \pm 8.11$ & 12.243 & .000 \\
Application of ethics post & $19.11 \pm 8.11$ & 12.243 & .000 \\
\hline
\end{tabular}

\section{Discussion}

Currently, psychiatric patients' ethical and legal rights are a key driver in healthcare. ${ }^{[15]}$ In nursing, concern for patient's rights is not new, with its roots tracing back to the 19th century when Nightingale announced her underpinning ideas of protecting patients from harm at bedside. Despite this interest, the ethical and legal aspects of psychiatric patients have not been clearly described in developing countries. Therefore, the current study examined the impact of an educational intervention in enhancing knowledge of nurses toward psychiatric patients' ethical and legal rights. The results of the current study revealed that, nurses' knowledge was inadequate and unsatisfactory in the pre assessment and has become satisfactory in post program intervention with high significant difference at $p \leq .05$. Therefore, the current study findings evidenced the effectiveness of the educational intervention in changing the knowledge of the nurses significantly as follows:

As regard to knowledge related to basic nursing ethics meaning, principles of bioethics and definition of informed consent, veracity and confidentiality; the nurse's knowledge was considered very deficient compared with the post intervention with a high significant difference at $p=.000$. Various interpretations could be given to the obtained results as this may be due to the fact that nurses did not have training courses concerning patient's rights, although they've had courses during their undergraduate studies. Moreover, the nursing ethics course in diploma level was often ignored, and the nursing staff were becoming insensitive to ethical issues 
in day-to-day nursing work. In addition, it is thought that many members of the nursing staff think that the psychiatric patients' needs should not be monitored at all times. This was in the same vein of findings of Hariharan et al. ${ }^{[16]}$ who discovered that many senior level staff did not think that, the patient's needs should be met at all times and showed the lack of knowledge in the basic principles of medical ethics due to their negative attitude toward psychiatric patients.

Furthermore, khalil and Dawood ${ }^{[17]}$ reported that, nurses who hold negative attitudes toward psychiatric patients, easily neglect that they have rights as other patients. The results also support the study done by Hafez, Mohammed and Sobeh ${ }^{[14]}$ who announced that the knowledge of nurses is very low in relation to basic knowledge of ethical patients rights.

This simply showed that, the curricular training regarding ethics and law pertaining to work in psychiatric hospitals is either inadequate or ineffective. Evermore, professional qualification and certification are important requirements to prepare any person to become a registered psychiatric nurse., Unfortunately, this is not practiced in the research setting due to the barriers of learning these skills where there are no educational agencies in the country that can provide special psychiatric nursing qualifications and certifications. Therefore, care providers are neither certified nor qualified to work with psychiatric patients, especially in emergency situations. Hence, this lack of education in the nursing staff is a hindrance in providing high-quality nursing care to the patients who need an advanced level of nursing care. ${ }^{[18]}$ The majority $(65 \%)$ of nurses working in the current study setting either had an associate degree of nursing (diploma) or BSC without specific qualifications in psychiatric nursing practices. In the same stream, Ryyen and Myllykangas ${ }^{[19]}$ stated that, nurses' knowledge of patients' rights is considered essential to provide patients with legal rights in fields concerning their care. This made healthcare workers legally responsible for treatments of their patients and maintaining their safety.

Ignorance of patients' rights are also due to the stigma of mental illness held by the public and medical professionals toward both patients and professionals working in psychiatric hospitals. Patients' rights therefore must be emphasized as one of the fundamentals of health care, as their implication affects many areas of human life. ${ }^{[20]}$ In regard to the effectiveness of the educational intervention in developing nurses' knowledge of basic concepts in nursing ethics and their application in nursing care, all nurses' responses were correct concerning the identification of the concepts of justice, confidentiality, non-maleficence, negligence, the intentional tort and the importance of getting the informed consent either from the patient or his guardians in the pre assessment with high significant difference between pre and post assessment at $t=14.47,8.651$; and 6.513 respectively with $p=.000$. These results correspond to the findings of Hafez, Mohammed and Sobeh ${ }^{[14]}$ who found that the minority of the studied nurses had satisfactory level of knowledge in relation to the concept and knowledge of bioethics and its application in the hospital.

Furthermore, the interpretation of the obtained results is related to negative attitude toward psychiatric patients as mentioned previously, as well as an inadequate knowledge and education level as the majority $(72.9 \%$ )of the nurses were diploma nurses. On the other hand, the obtained results were also related to the non-variability of the nurses in regard to their educational backgrounds and clinic experiences. It was observed that the newly appointed staff were taught by old non-qualified staff who held very annulling attitudes towards patients and always favored assault and the usage of restreints/seclusion even when patients' behaviors were not harmful. The same finding was obtained by Mann-Poll et al. ${ }^{[21]}$ who assessed knowledge and practice of nursing ethics and laws among nurses working in a teaching hospital in Nepal, and found that $50 \%$ of respondents had poor practice of nursing ethics and laws.

On the other hand, the results were contradicting to those obtained by Laabs, ${ }^{[22]}$ and Hafez, Mohammed and Sobeh ${ }^{[14]}$ who discovered that nurses had satisfactory level of practice of professional ethics, and an even better knowledge. Consequently, Hafez, Mohamed and Sobeh ${ }^{[14]}$ found that according to the participants, there was a statistically significant correlation between nurses' knowledge and practice scores. Therefore, the findings made it clear to upgrade nurses' knowledge and practice regarding ethics through educational programs and awareness concerning the code of ethics, ethical principles, and standards of nursing practice in clinical areas.

Another study was done by Demirsoy and Kirimlioglu ${ }^{[23]}$ on healthcare professionals at the Training and Research Hospital of the Faculty of Medicine, in Turkey, with the aim of determining healthcare professionals' (physicians' and nurses') attitudes towards the right of privacy and confidentiality, which are important components of patient rights. The research data were reported that nurses and physicians were informed about patient rights and strongly agreed with the protection of privacy, and the confidentiality of information related to patients, as a patient right. Therefore, with a view to protect and implement patients' rights, it is a must to inform and raise awareness of healthcare professionals about patients' rights, legal responsibilities of healthcare profes- 
sionals, and communication techniques. A lot of studies also showed the importance of continuing education and intensified efforts to ensure that staff nurses acquired the necessary knowledge that was needed to decrease the effects of misuse of law and negligence of psychiatric nursing practice. ${ }^{[24]}$

Moreover and with regard to the relation between nurses' total knowledge and practice of professional ethics and their personal characteristics, there were no statistically significant relations between staff nurses' practice and their educational qualification, marital status, attendance of psychiatric or ethics profession workshops and the study of ethics, with their knowledge level concerning ethical and legal practices in the field of psychiatric nursing (see Table 8). In the same vein, study results conducted by Kumar, Mehta and Kalra ${ }^{[6]}$ found no correlation between nurses' knowledge of ethics and their sex, marital status, or designation. Gallaghe ${ }^{[25]}$ also illuminated that nurses' age did not seem to contribute to their knowledge of nursing ethics.

However, the current study results asserted that psychiatric total clinical experience and age of the studied nurses ( $p$ $\leq .05$ ) were significantly related to their knowledge and practices regarding legal and ethical application responsibility. In addition, the current study results were in correspondence with Hafez, Mohammed, and Sobeh ${ }^{[14]}$ and Vanaki and Memarian, ${ }^{[26]}$ as their results demonstrated a positive relationship between nurses' age and years of experiences with their scores of practice and knowledge. They illustrated that nurse's age plays a significant role with their knowledge regarding ethics through an accumulation of experience. This interpretation was supported by Solminen, Numminien and Leino $^{[27]}$ who stated that there was an association between nurses' knowledge and their age. Moreover, Hariharan et al. ${ }^{[16]}$ claimed that profession experiences should be used to reinforce ethical practice and knowledge.

In this perspective, it was asserted that years of expertise and age had obvious effects on nurses' knowledge about the legal and ethical aspects of nursing practice, as these experiences provide a basis for nursing practice and help nurses to take decisions while minding the consequences of the universal moral principles, when making clinical judgments throughout their day. Likewise, Koshy ${ }^{[1]}$ found a statistically significant relation between nurses' knowledge and application of ethics and their age and working experiences. Therefore, it is simply obvious that there was a statistically significant relation between nurses' knowledge of professional ethics and their work setting experience (see Tables 8 and 9).

\section{Conclusion}

In the context of the current study findings, it has been concluded that nurses' knowledge was low and their practices were poor regarding the application of ethical and legal rights of psychiatric patients in the pre assessment, and have become high and satisfactory in the post program intervention with a high significant difference at $p \leq .05$. Therefore, the current study findings evidenced the effectiveness of the educational intervention in enhancing the knowledge of nurses significantly.

Moreover, the knowledge of studied nurses was severely deficient regarding the identification of concepts such as justice, confidentiality, non-maleficence, negligence, the intentional tort and the importance of getting the informed consent either from the patient or his guardians in the pre assessment with a high significant difference between pre and post assessment at $(t=14.47,8.651$; and 6.513 respectively with $p=$ .000). The nurses' applications of professional ethics and legal practices in psychiatric settings, is also very poor in relation to their ability to realize that every newly admitted patient has the right to orientation, confidentiality and giving consent. Nurses' age, educational qualification, marital status, attending psychiatric or ethics profession workshops had no relationship with their level of knowledge and practices. While, psychiatric total clinical experiences of nurses $(p \leq .05)$ were significantly related to their knowledge and practices of legal and ethical application responsibility.

\subsection{Recommendations}

- In-service training program on ethics, ethical decision making, and professional legislation in nursing is also crucial.

- Learning is strongly recommended through focus groups, workshops and the use of practical simulation in teaching ethics, particularly in a multidisciplinary setting.

- Regular conduction of awareness programs regarding the code of ethics, ethical principles and standards of nursing practices in psychiatric clinical settings are also strongly recommended especially with newly appointed staffs.

- In addition, nursing commission should have an effective role in monitoring and evaluating nurses' performance regarding the application of ethical and legal behaviors regularly. In this way, the application of such behavior through specific evaluation sheets for professional ethics is ensured. 


\subsection{Research implications}

- Patient ethical and legal rights should be printed on a big poster and exhibited clearly in each ward to make it available for patients and their families to read.

- A copy of the ethical and legal information booklet may be provided to all staff nurses during their orientation program. A copy should also be kept in each ward to serve as a reference in case of any discrepancy between the nurses, patients and the management.

- In-service education programs should be conducted periodically for nursing personnels, in order to help nurses update their knowledge regarding their legal re- sponsibilities when dealing with psychiatric patients.

- Director of the hospital and nursing administrators should empower nurses with adequate information booklet on legal responsibilities which would enable the nurses to act as patients' advocates and also prevent the loss of the hospital's management time and money, which may arise due to consumers prosecuting the hospital because of nurses' negligence and malpractices.

\section{CONFLICTS OF INTEREST Disclosure}

The authors declare that there is no conflict of interest.

\section{REFERENCES}

[1] Koshy P. A study to assess the knowledge regarding legal and ethical concepts in care of children among staff nurses in selected hospital in m.p. International Journal of Science and Research (IJSR). 2016; 5(9): 1454-1457.

[2] Aliyu1 D, Adeleke IT, Omoniyi SO, et al. Knowledge, attitude and practice of nursing ethics and law among nurses at Federal Medical Centre, Bida. American Journal of Health Research. 2015; 3(1): 3237. https://doi.org/10.11648/j.ajhr.s.2015030101.15

[3] Lilja L, Ordell M, Dahl A, et al. Judging the other: Psychiatric Nurses' Attitudes towards Identified Inpatients as Measured by the Semantic Differential Technique. Journal of Psychiatric and Mental Health Nursing. 2004; 11(5): 546-553. PMid:15450021 https://doi.org/10.1111/j.1365-2850.2004.00758.x

[4] Eklund M. Attitudes towards mental illness among health care students at Swedish universities - A follow-up study after completed clinical placement. Nurse Education Today. 2009; 29(6): 660-665. PMid:19286287 https://doi.org/10.1016/j.nedt.2009.02 .006

[5] Shrestha S, Jose P. Knowledge \& practice of nursing ethics and laws. Journal of Universal College of Medical Sciences. 2014; 2(7): 30-33. https://doi.org/10.3126/jucms.v2i3.11825

[6] Kumar R, Mehta S, Kalra R. Knowledge of stuff nurses regarding legal and ethical responsibilities in the field of psychiatric nursing. Nursing and Midwifery Research Journal. 2011; 7(1).

[7] Sanjari M, Zahedi F, Larijani B. Ethical codes of nursing and the practical necessity in Iran. Iranian Journal Public Health. 2008; 37(1).

[8] Iglesias ME, Vallejo RB. Nurse Attitudes in Relation to Health Care Ethics and Legal Regulations for Nursing. Acta Bioethica. 2014; 20(2): 255-264. https://doi.org/10.4067/S1726-569 $\mathrm{X} 2014000200013$

[9] Cortez E, Tavares C, Elias A. Impact of Stigma of Madness on the Attention of Nursing to Psychiatric Patient in Emergency Situation. Cienc Cuid Saude. 2013; 12(4): 776-783.

[10] Ulrich CM, Taylor C, Soeken K, et al. Everyday ethics: Ethical Issues and Stress in Nursing Practice. Journal of Advanced Nursing. 2010; 66(11): 2510-2519. PMid:20735502 https://doi.org/10.111 $1 / j .1365-2648.2010 .05425 . x$

[11] Cutcliffe JR. Whose life is it anyway? An exploration of five contemporary ethical issues that pertain to the psychiatric nursing care of the person who is suicidal: Part one. International Journal of
Mental Health Nursing. 2008; 17(4): 236-245. PMid:18666906 https://doi.org/10.1111/j.1447-0349.2008.00539.x

[12] Jane D. Development of an individual's ethical behavior. 2011.

[13] Osingada C, Nalwadda G, Ngabirano T, et al. Nurses' knowledge in ethics and their perceptions regarding continuing ethics education: a cross-sectional survey among nurses at three referral hospitals in Uganda. BMC Research Notes. 2015; 8: 319. PMid:26219840 https://doi.org/10.1186/s13104-015-1294-6

[14] Hafez F, Mohamed H, Eltabey D. Assessment of Nurses' Knowledge and Practice Regarding Professional Ethics in Outpatient Clinics at Mansoura. University Hospital. IOSR Journal of Nursing and Health Science (IOSR-JNHS). 2016; 5(6): 20-28.

[15] Runciman W, Hibbert P, Thomson R. Towards an international classification for patient safety: key concepts and terms. Int $\mathbf{J}$ Qual Health Care. 2009; 21(1): 18-26. PMid:19147597 https: //doi.org/10.1093/intqhc/mzn057

[16] Hariharan S, Jonnalagadda R, Walrond E, et al. Knowledge, attitudes and practice of healthcare ethics and law among doctors and nurses in Barbados. BMC Medical Ethics. 2006; 7(7): 1-9. PMid:16764719 https://doi.org/10.1186/1472-6939-7-7

[17] Khalil A, Dawood E. Physical restraints versus seclusion: patients 'preferences and perspectives, Menoufyia Nursing Journal. 2017.

[18] Al-Ahmadi H. Anticipated nurses' turnover in public hospitals in Saudi Arabia. The International Journal of Human Resource Management. 2014; 25(3): 412-433. https://doi.org/10.1080/09 585192.2013 .792856

[19] Ryyen O, Myllykangas M. Ethics in Health Care. 2000.

[20] Guido G, Watson A. Legal and ethical issues in nursing. 4th ed. Upper Saddle River, NJ: Pearson Prentice Hall; 2006.

[21] Mann-Poll P, Smit A, van Doeselaar M, et al. Professionals' Attitudes After a Seclusion Reduction Program: Anything Changed. Psychiatric Quarterly. 2012; 84(1): 1-10. PMid:22610382 https : //doi.org/10.1007/s11126-012-9222-6

[22] Laabs CA. Confidence and knowledge regarding ethics among advanced practice nurses. Nurs Educ Perspect. 2012; 33(1): 10-14. https://doi.org/10.5480/1536-5026-33.1.10

[23] Wojtowicz B, Hagen B, Daalen-Smith CV. No place to turn: Nursing students' experiences of moral distress in mental health settings. International Journal of Mental Health Nursing. 2013; 23(3). PMid:23980930 https://doi.org/10.1111/inm.12043 
[24] Demirsoy N, Kirimlioglu N. Protection of privacy and confidentiality as a patient right: physicians' and nurses' viewpoints. Biomedical Research. 2016; 27(4): 1437-1448.

[25] Gallagher. Essential of teaching and learning nursing ethics, perspectives and methods. 2006.

[26] Vanaki Z, Memarian R. professional ethics beyond the clinical
Competency. Professional Nursing Journal. 2009; 25(5): 285. PMid:19751933 https://doi.org/10.1016/j.profnurs . 200 9.01 .009

[27] Solminen L, Numminien O, Leino K. Nurses educators and professional ethics ethical principles and their implementation from nurse educators' perspectives. 2011. 